\title{
Fallopian Tube Leiomyosarcoma
}

National Cancer Institute

\section{Source}

National Cancer Institute. Fallopian Tube Leiomyosarcoma. NCI Thesaurus. Code C40128.

An aggressive malignant smooth muscle neoplasm, arising from the fallopian tube. It is characterized by a proliferation of neoplastic spindle cells. 